\title{
La primera iniciativa museística en La Rioja: El Museo de Antigüedades en la iglesia de San Bartolomé de Logroño en el siglo XIX
}

\author{
The first initiative to set up a museum in La \\ Rioja: \\ The Antiques Museum in Saint Bartholomew's \\ church in Logroño in the 19th century
}

Silvia LOSANTOS BLANCO

Recibido: 9-V-2014 / Aceptado: 15-VII-2014

Resumen: El Museo de Antigüedades en la Iglesia de San Bartolomé de Logroño, aunque proyecto frustrado, encarna el primer prototipo de museo en La Rioja y asimismo representa un precedente en la conservación del patrimonio histórico y artístico de la región. Su creación emana de un determinado contexto histórico del siglo XIX, el cual delimitó y creó las circunstancias culturales y legislativas para proteger el patrimonio cultural en España. Este siglo representa una fase de ensayos donde las circunstancias políticas, económicas y sociales entrarán en un ciclón de cambios y mediatizarán profundamente la promoción de unas soluciones incapaces de poner freno a una realidad desbordante de destrucción del patrimonio.

Palabras Clave: Iglesia de San Bartolomé, Logroño, Museo de Antigüedades, Desamortización, Patrimonio histórico y artístico, Siglo XIX.

ABSTRACT: The Antiques Museum in Saint Bartholomew's Church in Logroño failed as a project but it represents the first example of a museum in La Rioja. It is also a precedent with regard to the conservation of the region's historical and artistic heritage. The museum was set up in a very specific context in the 19th century that framed and gave rise to the cultural and legislative circumstances necessary to protect Spain's cultural heritage. That century was a testing period where political, economic and social factors were subject to vertiginous changes and were instrumental in promoting solutions that were unable to curb the rapid destruction of cultural heritage.

Key words: Saint Bartholomew's Church, Logroño, Antiques Museum, Disentailment, Historical and artistic heritage, 19th century. 
CONCIENCIA Y DESTRUCCIÓN DEL PATRIMONIO HISTÓRICO Y ARTÍSTICO DE LA IGLESIA EN EL SIGLO XIX

La conciencia sobre el patrimonio histórico y artístico en España surgió a partir de los ecos de la Revolución Francesa. Será Carlos IV con la Real Cédula de 1803 quien manifestase de manera temprana la necesidad de proteger los monumentos, sin embargo la consiguiente invasión napoleónica y Guerra de Independencia fueron especialmente devastadoras sobre el patrimonio eclesiástico ${ }^{1}$. Las tropas invasoras vieron en la destrucción del patrimonio de la Iglesia y de la aristocracia un acto catártico de la dominación de los grupos de poder, además de conseguir un precioso botín que haría las delicias de aristócratas y eruditos tanto en Francia como en el resto de Europa ${ }^{2}$. Pero serán los procesos desamortizadores iniciados con los gobiernos afrancesados ${ }^{3}$ y desarrollados en toda la centuria decimonónica bajo los distintos gobiernos liberales los que desencadenaron la mayor ruina y destrucción de este patrimonio en España ${ }^{4}$. Las desamortizaciones buscaron la transformación del país a nivel

${ }^{1}$ F. FERNÁNDEZ PARDO, Dispersión y destrucción del Patrimonio Artístico Español. Guerra de la Independencia (1808-1814). Volumen I, Madrid, 2007, especialmente capítulo XIII "La ruina de nuestra platería, tallas, marfiles y obras escultóricas", pp. 199-214, y capítulo XIX “Saqueo masivo de los monasterios y abadías", pp. 283-290.

${ }^{2}$ Sirvan como ejemplo las colecciones de arte que el general Soult o el general Wellington se llevaron como botín a sus respectivos países, citado por M. A. LÓPEZ TRUJILLO, Patrimonio. La lucha por los bienes culturales españoles (1500-1939), Gijón, 2006, pp. 148-149.

${ }^{3}$ M. J. REDONDO CANTERA, "La política bonapartista sobre los bienes artísticos del clero regular y su repercusión en un medio provincial: Valladolid, 18081813", Academia. Boletín de la Real Academia de Bellas Artes de San Fernando, no 73, 1991, pp. 255-258.

${ }^{4}$ Una visión general del tema F. TOMÁS Y VALIENTE, El marco político de la desamortización en España, Barcelona, 1997; F. SIMÓN SEGURA, La Desamortización Española del siglo XIX, Madrid, 1973. Y más recientemente y de manera monográfica las Actas del Simposium dirigido por F. J. CAMPOS Y FERNÁNDEZ DE SEVILLA, La desamortización. El expolio del patrimonio artístico y cultural de la Iglesia en España, Madrid, 2007. político, económico y social ${ }^{5}$, esto conllevó la revisión del papel del clero en la sociedad y economía de la época, la declinación de sus tradicionales funciones educativas, asistenciales y sanitarias, la extinción de sus beneficios fiscales o la supresión de su régimen de propiedad de manos muertas.

En el grupo de las primeras desamortizaciones se encuentra la labor de las Cortes de Cádiz ${ }^{6}$, aunque su proyecto no se consumaría hasta el Trienio Liberal (1820-1823) cuando se destruyó definitivamente el papel de la Iglesia ${ }^{7}$ como pilar fundamental del Antiguo Régimen ${ }^{8}$. En el siguiente proceso desamor-

${ }^{5}$ El tema de las desamortizaciones ha generado una abundante bibliografía, comenzamos por remitir el estudio general de historia económica de G. RUEDA HERNANZ, La desamortización en España: un balance (1766-1924), Madrid, 1997. El carácter de miscelánea y de historia comparada otorga un gran interés al libro de B. BODINIER, R. CONGOST y P. F. LUNA (eds.), De la Iglesia al Estado. Las desamortizaciones de bienes eclesiásticos en Francia, España y América Latina, Zaragoza, 2009. Por su especial referencia al patrimonio artístico desde planteamientos de historia social y económica, señalamos a J. BELLO VOCES, Frailes, intendentes y políticos. Los bienes nacionales 1835-1850, Madrid, 1997. Una visión amplia desde la historia del arte es la que ofrece F. FERNÁNDEZ PARDO, Dispersión y destrucción del Patrimonio Artístico Español. Desamortizaciones (18151868). Volumen II, Madrid, 2007. Como estudio sintético de un ámbito territorial destacaríamos J. M. BARRIOS ROZÚA, Las desamortizaciones y el Patrimonio Histórico de Andalucía, Sevilla, 2009.

${ }^{6}$ Las medidas adoptadas fueron las siguientes: la incautación de los bienes de la Inquisición tras su abolición, por Decreto de 22 de febrero de 1813; la extinción de las órdenes militares de Santiago, Alcántara, Calatrava y Montesa el 11 de agosto de 1811, y la de San Juan de Jerusalén, según Decreto de 13 de septiembre de 1813. En lo que respecta al clero regular, el 18 de agosto de 1809 se suprimieron varias órdenes regulares, monacales, mendicantes y clericales, así como se dispuso la enajenación de los bienes de las órdenes religiosas disueltas por los invasores franceses por el Decreto de 17 de junio de 1812. Y finalmente, el Decreto de 13 de septiembre de 1813 convirtió en bienes nacionales los pertenecientes a los jesuitas, las órdenes militares y los conventos arruinados y suprimidos en 1802.

${ }^{7}$ Decreto de 1 de octubre de 1820, Gazeta del Gobierno, $\mathrm{n}^{\mathrm{o}} 123$, de 29 de octubre de 1820 .

${ }^{8}$ J. FONTANA LÁZARO, Historia de España. La época del liberalismo, vol. 6, Barcelona, 2007, pp. 119-121. 
tizador desarrollado en los años 1835-1836 durante la Regencia de María Cristina (18331840) y los gobiernos progresistas del conde de Toreno y de Mendizábal, las medidas se sucedieron sin interrupción ${ }^{9}$. Mendizábal consideró la necesidad urgente de hacer una reforma más extensa ya que todavía era desproporcionado el número de casas monásticas con fincas amortizadas existentes, y convenía ponerlas en circulación para aumentar los recursos del Estado y abrir nuevas fuentes de riqueza ${ }^{10}$. Una vez que todos estos bienes estuvieron desamortizados, el proceso se ceró con su venta pública ${ }^{11}$. Además se creó por primera vez un régimen especial para conservar determinados edificios con valor artístico o histórico, categorizados como Bienes Nacionales por las leyes desamortizadoras. A continuación vendría la creación de la figura jurídica de "monumento nacional"12, abriéndose una definitiva política conservadora del patrimonio arquitectónico.

En 1836 Mendizábal amplió la desamortización a la supresión de todos los monasterios, conventos, colegios, congregaciones y demás casas de comunidad o de instituto religioso de varones y mujeres, incluidas las de clérigos seculares y órdenes militares existentes en la Península, islas adyacentes y posesiones de España en Áfri$\mathrm{ca}^{13}$. En paralelo creaba juntas en todas las cabeceras diocesanas para concretar el destino que debía darse a los edificios que habían sido monasterios y conventos, siempre

\footnotetext{
${ }^{9}$ Decreto de 4 de julio de 1835, Gaceta de Madrid, no 188, de 7 de julio de 1835. Instrucción del 13 de julio de 1835, F. HERNÁNDEZ HERNÁNDEZ, El patrimonio cultural: la memoria recuperada, Gijón, 2002, p. 90. Real Decreto de 25 de julio de 1835, Gaceta de Madrid, no 211, de 29 de julio de 1835 .

${ }^{10}$ Real Decreto de 11 de octubre de 1835, Gaceta de Madrid, nº 292, de 14 de octubre de 1835.

${ }^{11}$ Real Decreto de 19 de febrero de 1836, Gaceta de Madrid, nº 426, de 21 de febrero de 1836.

${ }^{12}$ I. ORDIERES DÍEZ, Historia de la Restauración Monumental en España (1835-1936), Madrid, 1995, p. 26.

${ }^{13}$ Real Decreto de 8 de marzo de 1836, Gaceta de Madrid, $\mathrm{n}^{\mathbf{0}}$ 444, de 10 de marzo de 1836 .
}

privilegiando un destino de utilidad para la nación ${ }^{14}$. Su labor desamortizadora concluyó al año siguiente al disponer la supresión de la contribución de diezmos y primicias, así como de todas las propiedades del clero secular, adjudicándolas a la nación y convirtiéndolas en bienes nacionales ${ }^{15}$. En esta ocasión se afronta una profunda reforma tributaria y la nacionalización de los bienes del clero secular. Este ciclo desamortizador se completó con Espartero y la ley de bienes del clero secular ${ }^{16}$ que resolvió el problema de la dotación de culto y clero, así como de los gastos de conservación y reparación de las iglesias parroquiales.

La normativa desamortizadora incluyó una consideración especial acerca de los bienes muebles que por su "rareza, valor o mérito artístico" convenía conservar, y por primera vez se reguló jurídicamente a favor de la creación de bibliotecas, archivos y museos de carácter nacional como depositarios de esos bienes y obras de arte que, bajo otras circunstancias, hubiesen sido destruidos. De hecho, el liberalismo desarrollado en materia financiera y cultural durante la Regencia de María Cristina, dio lugar a gran parte de los museos artísticos del siglo XIX. Por ello, la especificidad de la gran mayoría de los museos en España, los llamados nacionales y provinciales, se vinculan con una estrategia política global en el ámbito económico y con el desarrollo de una ideología laica y nacionalizadora, heredera directa de los principios de la Ilustración y de la Revolución Francesa.

Madoz inició en 1855 el último ciclo desamortizador al declarar en estado de venta "los prédios rústicos y urbanos, censos y foros pertenecientes al Estado, al clero, a las órdenes militares, a las cofradías, obras pías y santuarios, a los propios y comunes

\footnotetext{
${ }^{14}$ Real Decreto de 13 de septiembre de 1836, Gaceta de Madrid, nº 650, de 22 de septiembre de 1836.

${ }^{15}$ Ley de 29 de julio de 1837, Gaceta de Madrid, no 974, de 1 de agosto de 1837.

${ }^{16}$ Ley de 2 de septiembre de 1841, Gaceta de Madrid, no 2514 , de 4 de septiembre de 1841 .
} 
de los pueblos, a la beneficiencia y a la instrucción pública"17. Esta ley estuvo en vigor hasta finales de siglo a pesar de los diferentes cambios de gobierno. Tanto progresistas como moderados reconocían en ese momento la necesidad de acabar con la tenencia de manos muertas para alcanzar el desarrollo económico del país. Con la desamortización de Madoz se terminó el ciclo de las grandes desamortizaciones decimonónicas y se abrió la necesidad y el interés, por parte del Estado, de solucionar el problema que se le planteaba con el gran volumen de bienes artísticos e históricos, muebles e inmuebles procedentes del menguado patrimonio eclesiástico. Así en las últimas décadas del siglo la Iglesia empezaría a pedir de manera sistemática a la Administración la declaración de monumento naciona ${ }^{18}$ y ayuda económica para afrontar las obras de sus templos más importantes, las catedrales ${ }^{19}$.

\section{LA PROTECCIÓN DEL PATRIMONIO A TRAVÉS DE LAS COMISIONES DE MONUMENTOS}

Ante la dramática situación de abandono, destrucción y expolio del patrimonio eclesiástico desencadenada por el proceso desamortizador, el gobierno de Mendizábal creó las "Comisiones científicas y artísticas" $^{\prime 20}$. Fueron estas comisiones las primeras instituciones oficiales creadas para los fines concretos de recoger los objetos más valiosos desde el punto de vista artístico, hacer un inventario de los mismos y colocarlos en una biblioteca o museo, iniciando la fase embrionaria de los primeros museos provinciales de bellas artes. Este ordenamiento introducía la protección del patrimonio artístico, bibliográfico y documental nacional para impedir las exportaciones al extranjero

${ }^{17}$ Ley de 1 de mayo de 1855, Gaceta de Madrid, oㅡ 852, de 3 de mayo de 1855.

${ }^{18}$ Gaceta de Madrid, no 155, de 4 de junio de 1931.

${ }^{19}$ I. ORDIERES DÍEZ, Op. cit., pp. 189-192, 209-212.

${ }^{20}$ Real Orden de 27 de mayo de 1837, Gaceta de Madrid, no 907, de 28 de mayo de 1837. y tipificaba la necesidad de permiso expreso para su salida del país. Había que poner freno al mercado del arte procedente de España que abastecía las colecciones europeas desde principios de siglo. El éxito o fracaso de tan digna acción dependió directamente de la sensibilidad e iniciativa de los miembros de las juntas, de la escasa financiación y de la responsabilidad que asumiesen o dejasen de asumir las autoridades regionales designadas a tal efecto, ante la falta de compromiso legal por parte del Estado ${ }^{21}$.

La realidad de incuria respecto al patrimonio artístico no desapareció con las Comisiones científicas y artísticas por lo que se intentó una reactivación del proceso con la creación de las "Comisiones de monumentos históricos y artísticos" ${ }^{22}$. Su cometido fue establecido por unas instrucciones ${ }^{23}$ con unos objetivos en exceso ambiciosos para la escasa provisión de recursos técnicos, humanos y económicos con los que contaron. El gobierno tuvo unas pretensiones poco realistas, lo cual abocó al fracaso la efectividad y funcionalidad de estas comisiones desde el momento mismo de su origen. No obstante, su existencia tuvo sus logros ya que fueron los entes que dieron lugar a la creación de los archivos, bibliotecas y museos provinciales y evitaron en muchos casos la venta de esos bienes a particulares y anticuarios o su destrucción total. Además, asumieron competencias en materia de arbitrio sobre las obras y reformas a realizar en edificios históricos $^{24}$, convirtiéndose en los inspectores del patrimonio cultural a nivel provincial.

\footnotetext{
${ }^{21} \mathrm{M}$. BOLAÑOS ATIENZA, Historia de los museos en España, Gijón, 2008, p. 191.

${ }^{22}$ Real Orden de 13 de junio de 1844, Gaceta de Madrid, nํㅡㄴ 3568, de 21 de junio de 1844 .

${ }^{23}$ Real Orden de 24 de julio de 1844, Gaceta de Madrid, no 3605, de 28 de julio de 1844 .

${ }^{24}$ Junto a la Real Orden de 4 de mayo de 1850, estuvieron las Reales Órdenes de 24 de noviembre de 1865 y de 10 de abril de 1866, que establecían la obligatoriedad de consultar a la Comisión de monumentos para la realización de cualquier obra en un edificio de interés
} histórico-artístico. 
Las Comisiones provinciales se dedicaron fundamentalmente a la elaboración de inventarios y catálogos de los bienes muebles e inmuebles de su territorio, así como a denunciar las demoliciones y enajenaciones de estos monumentos por parte de particulares para beneficio propio. Es a partir de este momento cuando se puede hablar de una apuesta más decidida por parte del Estado en su labor de proteger los bienes artísticos y de crear una administración específica para dicho patrimonio, con el desempeño de unas mayores atribuciones. Si bien, las contradicciones se mantendrán con carácter generalizado en las distintas Comisiones provinciales, quedando invalidada la entrega y devoción casi vitalicia de los comisionados, debido a la penuria presupuestaria y al excesivo centralismo de su funcionamiento sometido a la Comisión Central. Puede ilustrar esta realidad el caso concreto de la comisión provincial de La Rioja donde sus miembros asumían el cargo a lo largo de toda su vida y se dejaba constancia de los fallecimientos al principio de las sesiones ${ }^{25}$.

Su larga existencia, durante casi cien años, se debe en gran medida a los cambios introducidos con sucesivas reformas y readaptaciones: $1854^{26}, 1857^{27}, 1865^{28}, 1918^{29}$. A pesar de los escasos recursos, debían ocuparse de las acciones prioritarias y urgentes, de la conservación de los edificios monumenta-

${ }^{25}$ J. J. B. MERINO URRUTIA, "Labor de la Comisión de Monumentos de La Rioja desde que fueron creadas el año 1845 hasta nuestros días", Berceo, nº 14, 1950, pp. 25-52, y no 15,1950 , pp. 327-356.

${ }^{26}$ Real Decreto de 15 de noviembre de 1854, Gaceta de Madrid, nº 685, de 17 de noviembre de 1854 .

${ }^{27}$ Ley de Instrucción Pública de 9 de septiembre de 1857, Gaceta de Madrid, nº 1710, de 10 de septiembre de 1857.

${ }^{28}$ Reglamento aprobado el 24 de noviembre de 1865.

${ }^{29}$ Las Comisiones provinciales perderían gran peso durante la Segunda República con la creación de la Junta Superior del Tesoro Artístico y las Juntas locales en 1933, manteniéndose algunas hasta su desaparición efectiva en 1936. En el periodo de posguerra algunas de ellas volvieron a aparecer, así lo apunta I. ORDIERES DÍEZ, Op. cit., p. 58. les, de sus restauraciones, y del sostenimiento de los museos, bibliotecas y archivos que se hubiesen establecido o se fuesen a constituir. Estas preocupaciones son una constante que se manifiesta en la labor concreta de las Comisiones provinciales a través de sus actas de reunión. En la Comisión provincial de La Rioja el tono alcanzaba la queja de manera habitual ${ }^{30}$.

Desde 1865 se crearía firmemente el procedimiento para la declaración de Monumento Nacional como instrumento de protección sobre el patrimonio arquitectónico, aunque no siempre fuese efectivo. Eran las Comisiones provinciales las encargadas de proponer los monumentos a proteger y posteriormente las Academias emitían el correspondiente informe ${ }^{31}$. Otro paso para procurar la conservación de los monumentos fue la profesionalización y especialización de los arquitectos en materia de restauración en la segunda mitad de la centuria ${ }^{32}$ y para el ámbito eclesiástico, de acuerdo a la importancia y volumen de sus monumentos, se crearía la figura del arquitecto diocesano ${ }^{33}$. Sin embargo las pretensiones legislativas y administrativas superaron la precaria realidad de la época fundamentada en el voluntarismo, las acciones puntuales y el esfuerzo individual de algunos personajes excepcionales.

“EL MUSEO DE ANTIGÜEDADES DE SAN BARTOLOMÉ" COMO INICIATIVA PRECURSORA EN MATERIA MUSEÍSTICA EN LA RIOJA

Hemos visto que durante el siglo XIX, e incluso el primer tercio del XX (hasta 1936),

${ }^{30}$ J. J. B. MERINO URRUTIA, Op. cit., $\mathrm{n} \stackrel{\mathrm{o}}{14}$, 1950, pp. $25-52$ y no 15,1950 , pp. 327-356.

${ }^{31}$ I. ORDIERES DÍEZ, Op. cit., pp. 85-86.

${ }^{32}$ Real Decreto de 1 de diciembre de 1858, Gaceta de Madrid, no 338, de 4 de diciembre de 1858. El Decreto organizaba el servicio de la Dirección de Obras Públicas y creaba las plazas de arquitectos provinciales. Su reglamento se aprobaba el 14 de marzo de 1860, Gaceta de Madrid, nํ7, de 17 de marzo de 1860.

${ }^{33}$ Real Decreto de 13 de agosto de 1876, Gaceta de Madrid, nº 230, de 17 de agosto de 1876 . 
los organismos concernientes en materia de patrimonio histórico y museos fueron las Comisiones Provinciales de Monumentos Históricos y Artísticos. La Comisión provincial de Logroño fue creada, como el resto, bajo la Real Orden de 13 de junio de $1844^{34}$. El idealismo teórico y la perspectiva utópica que las vio nacer chocaba frontalmente con la incapacidad dotacional, presupuestaria y humana de que disponían, realidad que fue extensible a la Comisión de Logroño. Sus atribuciones, en exceso optimistas, estaban encaminadas a formar catálogos, descripciones y dibujos de los monumentos y antigüedades que no fuesen susceptibles de traslación, a crear y cuidar archivos, museos y bibliotecas, a adquirir noticias de los edificios monásticos y antigüedades dignas de conservarse, o a reunir los objetos preciosos, literarios o artísticos pertenecientes al Estado, pero diseminados por la provincia, reclamando los sustraídos. A nivel provincial, en su larga existencia se experimentaron además momentos de inactividad o cuando menos de vacío documental, ya que no se conservan actas de las reuniones o cualquier otra documentación referente a su labor ${ }^{35}$. Algunas de estas fases son las comprendidas entre los años 1870 y $1882^{36}$, o entre 1917 y $1936^{37}$, años de los que no existen actas de reuniones, ni ninguna otra referencia.

\footnotetext{
${ }^{34} \mathrm{El}$ tema ha sido tratado de manera monográfica en esta región por J. J. B. MERINO URRUTIA, Op.cit. y por M. C. NAVARRO BRETÓN, "El Patrimonio Artístico Riojano en el siglo XIX, a través de la Comisión Provincial de Monumentos" en B. ARRÚE UGARTE (coord.), Aspectos menos conocidos del Arte Riojano (1997-1999), Logroño, 2000, pp. 191-216.

${ }^{35}$ La documentación existente sobre la Comisión provincial de Logroño se encuentra distribuida entre las siguientes instituciones: el Archivo de la Real Academia de Bellas Artes de San Fernando (en adelante ARASF), Comisión Provincial de Monumentos, La Rioja/102, 18351889, Legajo 2/49/1; el Archivo del Instituto de Estudios Riojanos (en adelante AIER), Legajo M/512; el Archivo del Museo de La Rioja (en adelante AMLR), Caja 18451868 y Caja 1869-1918 y el Archivo Histórico Provincial de La Rioja (en adelante AHPLR), Gobierno Civil, Legajo
} 8, "Libro de actas de la Comisión de Monumentos".

${ }^{36}$ J. J. B. MERINO URRUTIA, Op. cit., no 15, p. 327.

${ }^{37}$ Ibídem, p. 354.
Una de las atribuciones de la Comisión consistía en la elaboración de un inventario o catálogo monumental, tal y como se recomienda en los distintos reglamentos redactados durante el siglo XIX (1844, 1854 y 1865$)^{38}$. La realidad es que la Comisión provincial no concluyó ninguna de las órdenes emanadas desde la administración central competente en la materia, con esta finalidad concreta de realizar el catálogo de las riquezas artísticas de la provincia ${ }^{39}$. Esta labor no sería desarrollada por la Comisión, constituyendo una de sus misiones fallidas y frustradas. La solución vendría en 1915 cuando la Dirección de Bellas Artes designara a Cristóbal de Castro para realizar el Catálogo Monumental y Artístico de la provincia de Logroño ${ }^{40}$, tras haber realizado previamente los de Álava y Orense y obtener sobre los mismos un informe favorable. Bajo Real Orden de 1 de febrero se le concedía la realización del mismo con un plazo de ocho meses, por lo que cobraría ochocientas pesetas mensuales. Transcurrido el plazo pediría una prórroga de cuatro meses más, entregando finalmente el trabajo el 1 de febrero del año 1916, en dos volúmenes, uno de texto y otro de láminas con doscientas cincuenta y cuatro fotos. El hecho es que, tal como apunta Amelia López-Yarto ${ }^{41}$, los catálogos realizados por Cristóbal de Castro, un periodista de "profundísima ignorancia y osadía" en palabras de Gaya Nuño, son muy malos y aportan pocos datos, siendo lo más probable que ni siquiera realizase el mínimo trabajo de campo visitando los pueblos y sus monumentos. Entre los que le adjudicaron (Álava, Orense, Navarra, Canarias, Cuenca y Santander) se encuentra el de Logroño.

Las noticias y atenciones de la Comisión se centraron de manera casi exclusiva en una pequeña porción del patrimonio re-

\footnotetext{
${ }^{38}$ Véase notas 26, 27 y 28.

${ }^{39}$ M. C. NAVARRO BRETÓN, Op. cit., pp. 198-200.

${ }^{40}$ A. LÓPEZ-YARTO ELIZALDE, El Catálogo Monumental de España (1900-1961), Madrid, 2010, p. 54.

${ }^{41}$ Ibídem, p. 68.
} 
gional. La muestra se significó en los monasterios de San Millán de la Cogolla, Santa María la Real de Nájera, la Estrella de San Asensio y la iglesia de San Bartolomé y sus diferentes avatares para evitar su ruina, la falta de presupuesto para acometer las mínimas obras de mantenimiento, los usos diversos que contuvieron y la búsqueda de inquilinos dotados de la dignidad suficiente para garantizar su conservación, en este caso órdenes religiosas. Las piezas rescatadas de estos monasterios son las que constituyen en la actualidad los fondos más antiguos del Museo de La Rioja. De otros complejos religiosos como el convento de San Francisco de Nalda, el de San Francisco de Santo Domingo de la Calzada, el monasterio de las Bernardas de Herce, y los conventos de San Francisco, del Carmen y de la Merced de Logroño, apenas se da información ofreciendo referencias mínimas acerca de su ruina o de sus nuevos usos como cárceles, cuarteles, institutos o colegios. Sobre el resto, una laguna de silencio se abre quedando en la penumbra de la ignorancia y el abandono.

No obstante, entre las aspiraciones más claras de la Comisión se encontraba la de formar un museo que diese protección al patrimonio desamortizado y en peligro de desaparición que se encontraba en los monasterios comentados. Las referencias a este tema en las actas de la Comisión regional y en las recomendaciones de la Central son constantes y persistentes. Bajo este paraguas de circunstancias surgió la primera iniciativa de carácter museístico que se planteó desarrollar en la provincia de Logroño, con la creación del "Museo de Antigüedades Cristianas" en la iglesia de San Bartolomé. Esta idea tardó tres décadas en forjarse y aunque no llegó a materializarse, ejemplifica el espíritu de voluntades, indefiniciones y contradicciones propio del siglo XIX en materia de conservación del patrimonio histórico y artístico.

Este templo, en unión con el de San Blas, había sido suprimido en concepto de parroquias de acuerdo al plan de arreglo para el clero de la ciudad de Logroño, por el auto de 1 de julio de 1829, aprobado por Fernando VII el 6 de junio de $1830^{42}$. Esta medida no hacía sino ratificar una supresión efectiva anterior, ya que en 1822 el obispo de Calahorra había aprobado la demarcación de Logroño en tres parroquias: la Colegial, la Imperial de Santa María y Santiago el Real. San Bartolomé y San Blas, debido al estado de sus fábricas y el corto número de feligreses quedaron vacantes, por lo que fueron agregadas a las "tres únicas parroquias que han de subsistir" ${ }^{43}$. En 1834, la Subdelegación de Fomento de la provincia pedía noticias al obispado acerca de la utilidad y derechos que la Iglesia tenía en la conservación de esos templos. La motivación era darles un nuevo uso para lo cual, y de acuerdo con esta intención, el gobernador civil ordenaba en 1835 que quedasen ambas iglesias "expeditas para la colocación de las municiones y demás artículos de guerra" ${ }^{44}$. Los preparativos militares de la ciudad avanzaban con presura en plena guerra carlista. El interés de la Brigada de Artillería en ocupar el templo de San Bartolomé motivó que se retiraran los vasos sagrados y demás objetos muebles pertenecientes al culto divino, siendo trasladados a la iglesia Imperial de Palacio.

Una vez que la iglesia de San Bartolomé había sido desembarazada de toda función religiosa fue utilizada durante treinta años como almacén de distintos elementos, entre ellos dinamita, maderas, paja o carbón, lo cual representaba un uso poco adecuado y un potencial peligro para la conservación de "una de las parroquias más antiguas de Logroño" ${ }^{45}$. Es por ello que la Comisión Cen-

42 Archivo Diocesano de Calahorra (en adelante ADC), Asuntos Gubernativos Eclesiásticos, Legajo 6/818/9/4, Logroño, 31 de julio de 1834.

${ }^{43}$ E. SÁINZ RIPA, “La división de las parroquias de Logroño: el paso de un régimen de adscripción voluntaria y personal a régimen de domicilio o territorial", Berceo, no 100, 1981, p. 303.

${ }^{44}$ ADC, Asuntos Gubernativos Eclesiásticos, Legajo 6/818/9/6, Logroño, 1835.

${ }^{45}$ A. LÓPEZ FERNÁNDEZ, La iglesia de San Bartolomé de Logroño: historia de la conservación del monumento en 
tral de Monumentos, en un comunicado de 24 de agosto de $1848^{46}$, ya animaba a establecer un museo en la iglesia de San Bartolomé para conservar el propio edificio, en especial su portada y los objetos de arte que todavía guardaba. En septiembre de ese año incluso contaba con un presupuesto estimativo del coste de las obras necesarias para la habilitación de la iglesia como museo y del traslado de las piezas existentes en Logroño y de las que estaban en los Monasterios de San Millán, la Estrella y Nájera que debían llevarse. Este presupuesto ascendía a 17.940 reales $^{47}$.

El interés por dotar al futuro museo de contenido se muestra nuevamente en 1857 cuando la Comisión provincial reclama unos cuadros a don Cesáreo Villodas vecino de San Asensio, procedentes en origen del Monasterio de la Estrella, diciendo "deben figurar por su mérito artístico en el museo que la citada Comisión de Monumentos trata de instalar" ${ }^{\prime 4}$.

Bajo la ley de incautación del 1 de mayo de 1855 la iglesia de San Bartolomé, hasta entonces dependiente del cabildo de Santa María de Palacio ${ }^{49}$, se había convertido en bien nacional. Sin embargo, tanto la administración civil como la eclesiástica entendieron el valor artístico del templo y la necesidad de conservarlo $^{50}$. Para conseguirlo se optó desde 1861 por su devolución a la funcionalidad religiosa y titularidad clerical, lo cual no se contradecía con su posible destino a museo. La curia diocesana mostró un gran interés en

el siglo XIX, Logroño, 2013, pp. 149-150.

${ }^{46}$ J. J. B. MERINO URRUTIA, Op. cit., $\mathrm{n}^{\mathrm{o}}$ 14, p. 30.

47 AMLR, Caja: Comisión Provincial de Monumentos, 1845-1868, Legajo 1848/2, Logroño, 10 de septiembre de 1848. 1857.

${ }^{48}$ Ibídem, Legajo 1857/1. Logroño, 12 de enero de

${ }^{49}$ J. C. BILBAO DÍEZ, Las desamortizaciones de Pascual Madoz en la ciudad de Logroño y su partido judicial (1855-1856). Aportación al estudio de la propiedad en la zona a mediados del siglo XIX, Logroño, 1983, p. 215.

${ }^{50}$ AMLR, Caja: Comisión Provincial de Monumentos, 1845-1868, Legajo 1861/20. su recuperación, pero este hecho obligaba a la emisión por parte del Estado de una orden del gobierno ${ }^{51}$. En 1864 la Real Academia de Bellas Artes de San Fernando, informada por la Comisión provincial, daba cuenta del valor de la iglesia de San Bartolomé ofreciendo una amplia enumeración y descripción de su arte e instaba al gobierno civil de la provincia a tomar medidas al respecto ${ }^{52}$ :

“El templo de San Bartolomé que en lo antiguo fue parroquia y que por una serie de

51 ADC, Asuntos Gubernativos Eclesiásticos, Legajo 6/818/9/51. Logroño, 9 de noviembre de 1861. “El Señor Gobernador Eclesiástico de Calahorra en comunicación que me ha dirigido en 8 de agosto último, expone: que la iglesia de San Bartolomé de esta capital se halla sirviendo de almacén de paja, que es una de las parroquias más antiguas de Logroño y que desde su supresión está agregada a la Imperial de Palacio, a cuyo cuidado ha estado siempre, hasta que las oficinas de Hacienda pública la creyeron comprendida entre los bienes declarados nacionales. En atención a esto y que estará mejor conservada dicha iglesia solicita se le devuelva al clero. Pasada dicha comunicación a informe de la Administración de Propiedades y derechos del Estado dice: que a consecuencia de la ley de $1^{\circ}$ de mayo de 1855 se incautó de ella el Estado, en vista de las relaciones que facilitó el cabildo de Palacio, no pudiendo en su concepto cederse al clero sin que preceda la orden del Gobierno de S.M. que según el artículo 6o del Real decreto de 21 de agosto del año pasado para llevar a efecto el convenio celebrado con la Santa Sede en 23 de igual mes de 1859, debe considerarse el edificio en cuestión como permutable, por no hallarse en el día destinado al culto, pudiendo retenerlo el Señor Gobernador Eclesiástico para los usos que crea oportunos, imputando en su día sus productos a la dotación del clero. En su virtud y considerando que según documentos que obran en la Comisión Provincial de Monumentos Históricos y Artísticos tiene la iglesia de San Bartolomé reconocido mérito artístico especialmente su portada y los sepulcros de los Almendrones que contiene, así como las pinturas antiguas del altar inmediato, creo que sería conveniente devolverla a la autoridad eclesiástica para el plausible objeto que manifiesta con el encargo especial de que procure su conservación ya que tan recomendada está, no solo por la superioridad, sino por todos los amantes de las artes liberales. Lo que tengo el honor de elevar al superior conocimiento de V.I. a fin de que en su consecuencia se sirva determinar lo que estimare oportuno. Dios guarde a V.I. muchos años. Logroño 9 de noviembre de 1861".

52 AMLR, Caja: Comisión Provincial de Monumentos, 1845-1868, Legajo 1863/1. Logroño, 10 de diciembre de 1863. 
circunstancias y vicisitudes vino a perderse para el culto, para el servicio del vecindario y casi para el arte es quizá el monumento más notable que encierra la ciudad de Logroño: su portada es un precioso ejemplo de la arquitectura y escultura del siglo XIII, su interior desahogado de buenas proporciones y bella ornamentación, sus bellos sepulcros ojivales con estatuas yacentes y muchas figuritas de delicada escultura ejecutadas en los siglos XIV y XV, la decoración de las archivoltas y las cabecitas de ángeles ejecutadas con todo el primor de la época floreciente del siglo XVI, los caracteres de mayor antigüedad que ofrece la capilla mayor y las notables pinturas de algunos de sus retablos son otros tantos objetos o detalles que hacen sumamente interesante este templo para el estudio razonado y filosófico de la Historia del Arte. Por estas razones, que ya tomó en consideración la suprimida Comisión central de Monumentos, se ha hecho presente más de una vez al Gobierno de S.M. la conveniencia de que este edificio se declarase monumento artístico digno de conservarse y como tal se pusiese bajo la inspección de la Comisión provincial del ramo. Esta necesidad es cada vez mayor pues arrendado el edificio a un particular que lo tiene destinado a almacén de paja y depósito de carruajes se encuentra todos los días expuesto a perecer, devorado por un incendio sin contar con lo impropio de tan humilde destino y con los desperfectos que le ha de producir naturalmente en sus delicados elementos decorativos. La Academia, que no puede creer que la escasa renta que su arrendamiento producía al erario público pueda mirarse por nadie como causa bastante para permitir que este interesante monumento perezca y se destruya, no puede menos en cumplimiento de su deber e instituto, de llamar la ilustrada atención de V.E. y rogarle se sirva interponer su eficaz influencia para que de acuerdo con el Ministerio de Hacienda se declare dicho edificio monumento del Estado y en su consecuencia se ponga bajo la tutela y vigilancia de la Comisión provincial, sin que esto obste para que al mismo tiempo pueda utilizarse ya abriéndolo al culto ya destinándolo a Museo provincial como en otra ocasión se pensó o a otro uso semejante y decoroso. Lo que traslado a V.E. como Presidente de esa Comisión de Monumentos para su conocimiento. Dios guarde a V.E. Madrid, 9 de febrero de 1864. El Secretario general. Eugenio de la Cámara. Sr. Gobernador Presidente de la Comisión de Monumentos de Logroño" ${ }^{\prime 23}$.

En esta ocasión, la Real Academia pedía encarecidamente al gobernador civil de Logroño la conveniencia de declarar el edificio como monumento artístico y en consecuencia ponerlo bajo la tutela y vigilancia de la Comisión provincial, sin perjuicio de que pudiese utilizarse para abrirlo al culto o para destinarse a museo provincial, en cualquier caso, cualquier otro uso que fuese digno y diferente de los que había venido sufriendo en los últimos años. A pesar de ello, en 1865 la iglesia de San Bartolomé seguía siendo arrendada por la Hacienda Nacional como almacén, en esta ocasión de carbón, hecho denunciado por el clérigo Manuel Sáenz ${ }^{54}$, personaje que tomará un cierto protagonismo dentro del obispado como defensor de la conservación de San Bartolomé.

Finalmente, el Ministerio de Hacienda dictaba el 22 de agosto de 1866 la Real Orden que comunicaba la excepción de la iglesia de San Bartolomé, en manos hasta entonces de la Administración, para destinarla de nuevo al culto público y conservar así su extraordinario mérito artístico. Destino que había sido pedido por el Arquitecto y Comisión de monumentos históricos de la provincia, la Real Academia de San Fernando y el Ministerio de Fomento que encarecían la necesidad de conservar el citado edificio "como monumento notabilísimo y en extremo interesante por las bellezas que contiene para el estudio razonado y filosófico de la Historia

53 ADC, Asuntos Gubernativos Eclesiásticos, Legajo 6/818/9/52. Madrid, 9 de febrero de 1864.

${ }^{54}$ Ibídem, Legajo 6/818/9/53. Logroño, 2 de octubre de 1865. AMLR, Caja: Comisión Provincial de Monumentos, 1845-1868, Legajo 1865, Logroño, 25 de octubre de 1865. 
del Arte" ${ }^{\prime 55}$. La Real orden aplicaba la excepción, debiendo hacerse la oportuna baja en la liquidación que se debía practicar de los bienes sujetos a la permutación en la Diócesis de Calahorra, entendiéndose que en caso de que el prelado no le diese el destino para el que había sido solicitada dicha excepción o dejase de atender a su conservación, quedaría de manera inmediata bajo la vigilancia de la Comisión de monumentos históricos y artísticos de la provincia.

El proceso institucional culminó en su declaración como monumento el 18 de septiembre del mismo año, siendo el primero de la provincia de Logroño ${ }^{56}$. Unos meses más tarde, el 2 de mayo de 1867, se realizaba el acta de entrega del "edificio que fue iglesia de San Bartolomé" por parte del Administrador de la Hacienda Pública al canónigo de la iglesia colegial Manuel Sáenz ${ }^{57}$. Ambos daban cuenta ante el notario eclesiástico del pernicioso efecto causado por los diferentes usos a que había sido destinado el edificio reconociendo que "solo se han conserbado en buen estado y en fuerza de su solidez las paredes y la nave; ni se encuentra objeto alguno de madera, ni ninguno de los retablos, a no ser el del altar mayor, esta con muchas piezas sueltas, y a falta de algunas; tampoco existen el pavimento y escaleras de piedra que conducían al altar mayor, observándose por las señales de la bóveda de piedra, que las aguas llovedizas penetran por el tejado, porque carece de algunas maderas y muchas tejas". Los considerables desperfectos que sufría el edificio hacían necesarias numerosas obras para su recuperación como templo.

Tan sólo tres meses después de la entrega de las llaves el mismo canónigo escribiría al obispado opinando sobre la idoneidad de dedicar parte del templo a museo de antigüedades cristianas:

${ }^{55}$ Ibídem, Legajo 6/818/9/60. Madrid, 14 de septiembre de 1866 .

${ }^{56}$ Sobre la base documental de la fecha de declaración véase A. LÓPEZ FERNÁNDEZ, Op. cit., p. 157.

57 ADC, Asuntos Gubernativos Eclesiásticos, Legajo 6/818/9/74. Logroño, 2 de mayo de 1867.
“[...] sin el menor reparo y sin obstáculo al culto y oficios divinos, sin deformidad de la iglesia, antes bien sirviéndola de adorno, puede dedicarse exclusivamente para este objeto la capilla primera de la nave derecha, en que se hallan dos sepulcros de reconocido mérito artístico e histórico, además del especial que contiene toda la iglesia, con tal que la Junta de Monumentos o el Gobierno costee los gastos de su restauración, y conservación y se hagan con intervención del sacerdote a quien V.S.Y. tiene encargado o encargare el cuidado del templo, conviniendo ambos en que bajo de este supuesto y sin perjuicio de las regalias episcopales puede V.S.Y. acceder y proponerlo para museo de antigüedades cristianas" ${ }^{\prime \prime}$.

La tendencia a nivel nacional de crear museos en templos había partido de la Comisión de Monumentos de Barcelona al señalar la conveniencia de disponer la Capilla de Santa Águeda como "museo de antigüedades cristianas"59. Esta actuación había sido respaldada por la Real Academia de Bellas Artes que propondría entonces que todas las provincias tuviesen el suyo propio. La Dirección General de Instrucción Pública dispuso así que las Comisiones de Monumentos, de acuerdo con el/los obispo/s cuyas diócesis formasen parte de la provincia, propusieran el templo más artístico de la capital de la misma, como el lugar más idóneo donde establecer el mencionado museo. La formación de los museos provinciales de Bellas Artes y Antigüedades, quedaría definitivamente establecido en el Reglamento de las Comisiones Provinciales de Monumentos Históricos y Artísticos, aprobado en la Real Orden de 24 de noviembre de $1865^{60}$. El capítulo IV: "De los Museos provinciales" (arts. 32-41), establecía el origen de las colecciones (bienes nacionales fruto de las desa-

\footnotetext{
${ }^{58}$ Ibídem, Legajo 6/818/9/75. Logroño, 4 de agosto de 1867.

${ }^{59}$ Ibídem, Legajo 6/818/9/71. Burgos, 22 de julio de 1867.

${ }^{60}$ Gaceta de Madrid, nº 345, de 11 de diciembre de 1865.
} 
mortizaciones, adquisiciones o donaciones), el personal responsable de su cuidado en la figura del "conservador" con el desarrollo de sus funciones, la apertura al público y a los investigadores, un incipiente modelo de presentación a través de cartelas y el centralismo para aquellos objetos de especial significación que debían ser trasladados a Madrid.

De acuerdo con estos requisitos, el templo elegido en la provincia de Logroño fue el templo de San Bartolomé. El propio gobernador civil visitaría la iglesia en agosto de $1867^{61}$, y la Comisión provincial de monumentos históricos y artísticos daría su visto bueno para su designación como el lugar más a propósito donde instalar el museo ${ }^{62}$. El obispo dio su conformidad a continuación y dispondría al canónigo Manuel Sáenz como interlocutor para realizar las obras que fuesen necesarias para tal fin y por extensión para abrir el templo al culto ${ }^{63}$. En abril de 1868 la iglesia de San Bartolomé estaba habilitada y restaurada para procederse a su bendición y reconciliación ${ }^{64}$, hecho que se producía en los primeros días del mes de mayo, bajo la rectoría y custodia del mencionado canónigo $^{65}$, el cual comunicaba que en el templo se decía "misa diaria y el rosario por la tarde con asistencia y aprovechamiento de los fieles" ${ }^{\prime 66}$. Sin embargo, el destino de San Bartolomé como museo de antigüedades cristianas no llegaría nunca a ser una realidad. En este caso, la responsabilidad de alcanzar tal fin recaía directamente so-

61 ADC, Asuntos Gubernativos Eclesiásticos, Legajo 6/818/9/76. Logroño, 9 de agosto de 1867.

${ }^{62}$ Ibídem, Legajo 6/818/9/77. Logroño, 31 de agosto de 1867.

${ }^{63}$ Ibídem, Legajo 6/818/9/78. Calahorra, 3 de septiembre de 1867. 1868.

${ }^{64}$ Ibídem, Legajo 6/818/9/85. Logroño, 22 de abril de

${ }^{65}$ Ibídem, Legajo 6/818/9/86. Logroño, 4 de mayo de 1868.

${ }^{66}$ Ibídem, Legajo 6/818/9/87. Logroño, 4 de mayo de 1868. bre la Comisión provincial, ya que entraba directamente entre sus competencias, por mucho que la buena disposición por parte del obispado existiese ${ }^{67}$. Las circunstancias que impidieron su materialización nos son desconocidas aunque todo apunta a la incapacidad humana y económica de la propia Comisión provincial.

El Museo de Antigüedades hubiese visto su perfecta materialización en un edificio histórico y monumental de carácter religioso como era la iglesia de San Bartolomé. Este intento fallido muestra el primer acto de una nueva escenificación, la protección y valoración del patrimonio mueble de la provincia, especialmente de origen eclesiástico, bajo la bóveda de un museo. Esta idea se irá injertando en sucesivas secuencias contextuales, intentando su perfecta germinación y floración.

La idea primigenia del Museo de antigüedades cristianas no culminó con su definitiva gestación, a pesar de las buenas disposiciones y posibilidades que se ofrecían desde todos los agentes implicados para ser instalado en la iglesia de San Bartolomé. Este objetivo de crear un museo tendría una azarosa trayectoria que no terminó de cuajar, aunque finalmente se eligiese hacia 1889 la ubicación del recién construido edificio de la Beneficiencia como el lugar más apropiado donde exponer los objetos acopiados por la Comisión ${ }^{68}$. En 1890 se trasladaban a la Beneficiencia los bienes que se habían ido recogiendo ${ }^{69}$, desde el Instituto de Segunda Enseñanza de Logroño, donde habían

${ }^{67}$ Véase el Capítulo IV: De los Museos provinciales, del Reglamento de las Comisiones Provinciales de Monumentos Históricos y Artísticos, establecido mediante Real Orden de 24 de noviembre de 1865 (Gaceta de Madrid, $\mathrm{n}^{\circ}$ 345, de 11 de diciembre de 1865).

${ }^{68}$ AMLR, Caja: Comisión Provincial de Monumentos, 1869-1918, Legajo 1889. Logroño, 14 de diciembre de 1889.

${ }^{69}$ Ibídem, Legajo 1890/3. Logroño, 22 de noviembre de 1890. 
permanecido almacenados ${ }^{70}$. Sin embargo, esta primera instalación no debió de existir durante mucho tiempo y nuevamente estos bienes se dispersaron entre distintos lugares donde fueron almacenados sin poder ser contemplados por el público ${ }^{71}$. En 1902 aparecerá otra idea que tratará de reunirlos en un solo edificio de Logroño, el Museo Provincial de Bellas Artes y el de Reproducciones Artísticas ${ }^{72}$.
Finalmente, la creación del Museo Provincial no se hizo realidad hasta $1963^{73}$, teniendo como base los fondos recogidos por la Comisión provincial procedentes de los conventos y monasterios desamortizados, materiales arqueológicos de excavaciones realizadas en los años treinta y cuarenta, así como objetos etnográficos. Sin embargo, su apertura al público no fue efectiva hasta el año $1971^{74}$.
${ }^{70}$ Ibídem, Legajo 1890/1. Logroño, 1 de noviembre de 1890 .

${ }^{71}$ J. J. B. MERINO URRUTIA, Op. cit., no 15, p. 336.

${ }^{72}$ M. J. ESCUÍN GUINEA, "Sobre los museos y su situación en La Rioja" en B. ARRÚE UGARTE (coord.), Op.cit., p. 14.
${ }^{73}$ M. T. SÁNCHEZ TRUJILLANO, "Los museos en La Rioja" en Actas del VI Congreso Nacional de ANABAD. Archivos, Bibliotecas, Centros de Documentación y Museos en el Estado de las Autonomías, Murcia, 1997, p. 671.

${ }^{74}$ M. J. ESCUÍN GUINEA, Op. cit., p. 14. 